\title{
Assessment of Level of Susceptibility of Anopheles gambiae S.L to Public Health Insecticides in a Malaria Vector Sentinel Site, Rivers State, Nigeria
}

\author{
N. Ebere ${ }^{1^{*}}$, I. Atting ${ }^{2}$, I. Ekerette ${ }^{1}$ and A. Nioking ${ }^{1}$ \\ ${ }^{1}$ Department of Animal and Environmental Biology, Rivers State University, Port Harcourt, Nigeria. \\ ${ }^{2}$ Department of Medical Microbiology and Parasitology, Faculty of Clinical Sciences, University of \\ Uyo, Uyo, Akwa Ibom State, Nigeria.
}

Authors' contributions

This work was carried out in collaboration among all authors. Author NE performed the statistical analysis, wrote the protocol and wrote the first draft of the manuscript. Authors IA and IE managed the analyses of the study. Author AN managed the literature searches. All authors read and approved the final manuscript.

Article Information

DOI: 10.9734/ARRB/2019/v32i130071

Editor(s):

(1) Dr. Gunanidhi Dhangadamajhi, Department of Biotechnology, North Orissa University, India.

(2) Dr. George Perry, Dean and Professor of Biology, University of Texas at San Antonio, USA. Reviewers:

(1) Anonymous, Tunisia.

(2) Dr. Gurjeet Singh, Pandit BD Sharma University of Health Sciences, India. Complete Peer review History: http://www.sdiarticle3.com/review-history/46056

Original Research Article

Received 14 March 2019

Accepted 26 May 2019

Published 11 June 2019

\section{ABSTRACT}

Aims: To investigate the status of susceptibility of Anopheles gambiae sensu lato (Diptera: Culicidae) mosquitoes to the WHO-approved insecticides for indoor residual spraying in field collected samples in a malaria vector sentinel site in Nigeria and Ts to provide an update on the current status of resistance to the major insecticide classes in wild populations of Anopheles gambiae sensu lato

Study Design: Field and laboratory -experimental design was used in this study.

Place and Duration of the Study: The study was carried out at a malaria surveillance site, established by the National Malaria Elimination Programme at Oduoha-Emohua in Rivers State, between April to September, 2015. 
Methodology: Anopheles larvae were collected from stagnant pools around the malaria surveillance site. The mosquitoes were reared to adulthood in the insectary and identified using morphological keys. Two- to three-day old adult female mosquitoes were exposed to standard diagnostic doses of Deltamethrin, Lambdacyhalothrin, Alphacympermethrin, Permethrin, Bendiocarb, Propoxur, DDT and Premiphos-Methyl using standard WHO protocols, insecticide susceptibility test kits and treated papers. Knockdown every $10 \mathrm{~min}$ and mortality $24 \mathrm{~h}$ post exposure was noted. All Anopheles mosquitoes tested belonged to the Anopheles gambiaecomplex.

Results: Mortality results indicated that the vectors were susceptible to Bendiocarb and Alphacympermethrin with mortality rates of $100 \%$ and $98 \%$ respectively. There was complete resistance to Deltamethrin, Lambdacyhalothrin, Permethrin, Propoxur, DDT and Premiphos-Methyl with mortality ranges of $25 \%-65 \%$.

Conclusion: The present study shows the effectiveness of Bendiocarb and Alphacympermethrin in malaria control with indoor residual spraying. It also provides baseline information for monitoring the status of insecticide resistance in Rivers State.

Keywords: Anopheles gambiae; susceptibility; insecticides; Rivers State.

\section{BACKGROUND}

Malaria is a life threatening disease in the tropics and which accounts for much of the disease burden in the Africa and is transmitted by female Anopheles mosquitoes.

In Nigeria, malaria is highly endemic and has claimed thousands of lives and caused massive economic losses $[1,2]$.

Malaria control is reliant on insecticides to supress the mosquito vector. In view of this, World Health Organization (WHO) has approved certain classes of insecticides to be used in their formulation namely, pyrethroids for both LLINs (long -lasting insecticidal nets) and IRS (indoor residual spraying) and organophosphates, carbamates and organochlorides solely for IRS [3].

Because of the intense selection pressure caused by agricultural practices [4] and the large-scale implementation of malaria vector control interventions [5], resistance has been implicated in the reduced efficacy of vector control interventions such as IRS and LLIN $[6,7]$ and malaria resurgence $[8,9,10,11,12]$.

Insecticide resistance in malaria vectors is a growing concern requiring immediate attention in many countries because of the limited chemical arsenal available for vector control. The global malaria community is responding to the potential threat posed by emerging insecticide resistance and in May, 2012, WHO launched the global plan for insecticide resistance management in malaria vectors (GPIRM), which includes planning and implementing a National Insecticide Resistance Management Strategy [13] Nigeria has joined other African countries in adopting an insecticide resistance management plan. The plan involves the setting up of sentinel sites for the routine monitoring of insecticide resistance by renowned research institutions in the country.

The current extent and distribution of this resistance in many parts of the continent is unknown and yet such information is essential for the planning of effective malaria control interventions [14].

The mechanisms of insecticide resistance in mosquitoes are multiple and include behavioural and physiological changes leading to insecticide avoidance, reduced penetration, sequestration, target site modification (knockdown resistance or kdr mutation for pyrethroids and DDT) and increased biodegradation $[15,16,17]$.

To effectively utilize insecticides in malaria vector control, it is pertinent to know the levels of insecticide resistance in the main malaria vector. Comprehensive evaluation of insecticides resistance across different malaria-endemic areas will provide critically needed data on use of new IRS strategies as alternative malaria control tools for further reducing malaria incidence in Africa [18].

Routine monitoring of resistance and detection of temporal changes in both prevalence and intensity of resistance are needed to guide malaria vector interventions and resistance management plan [12]. 
At present, there is insufficient data about the susceptibility status of malaria vectors to Public Health insecticides in the Niger delta region as compared to other areas of the country. This lack of data is a major constraint in the efforts to effectively control malaria vectors in the region.

Thus, the objective of this study was to provide an update on the current status of resistance of the main malaria vector (Anopheles gambiae S.I) to the major insecticide classes at the Rivers State sentinel site.

\section{METHODS}

\subsection{Study Site}

The study was conducted at Oduoha-Emuoha community. Emuoha is the headquarters of Emuoha Local Government Area of Rivers State and is one of the malaria endemic zones in the state. It is located in the Niger Delta region of
Nigeria and lies between: $04^{\circ} 52^{\prime} 44^{\prime \prime} \mathrm{N} 06^{\circ} 51^{\prime} 40 " \mathrm{E}$ (see Fig. 1). The environment is a typical tropical rain forest. The topography is flat and pockets of forest stream and fresh water bodies are found. The climate is characterized by two distinct seasons-, the wet and dry seasons, with the former taking place from April to October and latter between November and March.

\subsection{Larval Collection}

Larvae were collected by searching different types of Anopheles larval breeding sites around the sentinel site, using a dipping method described by World Health Organization.

All the potential breeding sites were surveyed for Anopheles larvae. A white iron dipper (ladle) was used for larvae collection. The GPS locations of the larval collection sites including some characteristics of the breeding sites, were recorded.

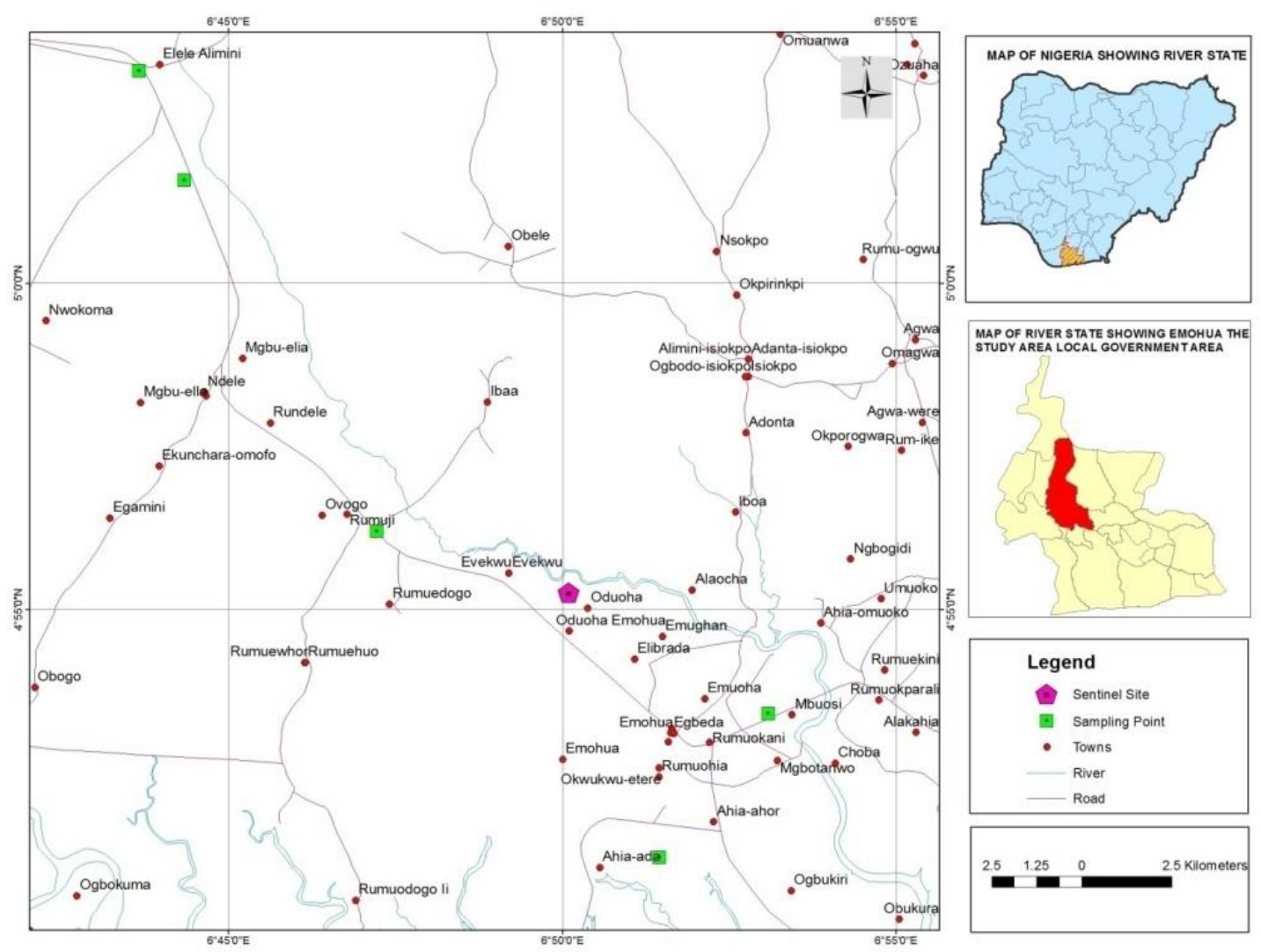

Fig. 1. Map of the study area showing the sampling locations 
The water containing the larvae from various areas was pooled together and transferred into a $20 \mathrm{~L}$ plastic container and transported to the insectary for identification and rearing.

The emerged adults were used for susceptibility tests.

\subsection{Rearing of Larvae}

The larvae were reared in the Malaria Entomology Research Laboratory, Rivers State University of Science and Technology, Port Harcourt under ambient laboratory environmental condition. The female Anopheles larvae were sorted out and put in plastic containers containing rearing water. The containers were covered with nets fastened with rubber bands and placed on a platform containing water to prevent crawling insects from invading the larvae. The larvae were fed with wheat powder mixed with ground biscuits and monitored until they were close to emergence.

\subsection{Rearing of Adult Mosquitoes}

The emerged adults were introduced into wooden rearing cages and fed with glucose solution. Two to three day old Anopheles female mosquitoes were aspirated out and used for a susceptibility test.

\subsection{Morphological Identifications Mosquitoes}

Female adult mosquitoes used for the susceptibility test were subjected to morphological identifications using the keys of Gillies and de meillon [19] and Gillies and Coetzee [20].

\subsection{Susceptibility Tests}

Insecticide susceptibility tests were carried out using the standard WHO protocol [21].

\subsection{WHO Susceptibility Test Procedure}

WHO Insecticide susceptibility test kits and impregnated papers were used for this test. Two to three day old non blood-fed adult female Anopheles mosquitoes collected around the sentinel site were tested. Batches of 25 mosquitoes were exposed to test papers impregnated with Permethrin $(0.75 \%)$, Deltamethrin $(0.05 \%)$ Alphacympermethrin $(0.75 \%)$, Lambdacyhalothrin $(0.05 \%)$, Propuxur $(0.05 \%)$, Bendiocarb $(0.13 \%)$ DDT $(4.0 \%)$ and Premiphos-Methyl (0.25\%).
Each insecticide was replicated 4 times. A total of 100 adult female Anopheles mosquitoes were tested for each insecticide. Two control experiments with the same batch (i.e 25 each) of mosquitoes from the site were carried out for each insecticide at the same time. In this case, the mosquitoes were exposed to untreated papers impregnated with mineral oils. The experiment was placed on a platform surrounded with water to prevent crawling insects from eating up the mosquitoes. The knockdown effect of each insecticide was recorded every 10 minutes over the one hour exposure period. A mosquito is considered knocked down if it is unable to stand or fly in a coordinated way. After the exposure, mosquitoes were then transferred to a recovery tube and provided with $10 \%$ glucose solution. Final mortality was recorded 24 hours post-exposure. A mosquito was classified as dead if it was immobile or unable to stand or fly in a coordinated way.

The mosquitoes used for the tests were preserved individually in Eppendorff tubes, labeled appropriately for identification and further analysis.

\subsection{Data Analysis}

Knock-down time (KDT ${ }_{50}$ and $\mathrm{KDT}_{95}$ ) along with slope and $95 \%$ confidence interval $(\mathrm{Cl})$ were determined using Probit analysis software.

The mortality of test sample was calculated by summing the number of dead mosquitoes across all four exposure replicates and expressing this as a percentage of the total number of exposed mosquitoes.

ObservedMortality $=$

$\frac{\text { Total Number of Dead Mosquitoes }}{\text { Total sample size }} \times 100$

The susceptibility levels of the mosquitoes were evaluated on the basis of the [22] criteria for test mortality. Correction with Abbots formula was not used as the mortality in all the controls was below $5 \%$.

\section{RESULTS}

\subsection{Knock- down Effect}

The Knock Down (KD) effect of the 8 insecticides tested over a 1- hour period is presented in Table 1 whereas the percentage knock -down effects is represented in Fig. 2 
The $\mathrm{KD}_{50}$ ranged from 9.3 to 80.9 minutes while the $\mathrm{KD}_{95}$ ranged from 16.6 to 149.8 minutes for all insecticides tested. The least knockdown effects were noticed in the vectors exposed to Bendiocarb and Alphacympermethrin insecticides treated papers with a rapid knock down within 10 minutes of exposure. The percentage knock downs of both insecticides at 10 minutes were $36 \%$ and $64 \%$ respectively. Within 30 minutes exposure, both insecticides knocked down all the mosquitoes exposed to them. Similarly, the KDT 50 of both insecticides was 15.4 and 9.0 minutes respectively while the $\mathrm{KDT}_{95}$ was 32.4 and 19.6 minutes respectively.

The knock down effects of the remaining insecticides were slow. Only Deltamethrin recorded $84 \%$ knockdown after 60 min exposure to the insecticide. The rest of the insecticides apart from Propoxur $(51 \%$ at 60 minutes) ,were unable to knock down half of the population of the vectors within the 1 hour period. PrimiphosMethyl and Lambdacyhalothrin had $\% \mathrm{KD}_{1 \mathrm{~h}}$ of $46 \%$ and $36 \%$ respectively. Permethrin and DDT had the least $\% \mathrm{KD}_{1 \mathrm{~h}}(14 \%$ and $22 \%$ respectively) and higher $\mathrm{KD}_{50}$ of 83.8 and 80.9 minutes respectively. The $\mathrm{KD}_{95}$ for both insecticides was 176.6 minutes (Permethrin) and 170.4 minutes (DDT). The $K \mathrm{D}_{50}$ for the remaining insecticides, Primiphos- Methyl, Propoxur, Lambdacyhalothrin and Deltamethrin ranged from 41.9-61.7minutes while the $\mathrm{KD}_{95}$ ranged from 83.3-130 minutes.

\subsection{Percentage Mortality}

Percentage mortalities after the 24 hour post exposure period are presented in Tables 1 . In all the cases the control mortality was less than $5 \%$, therefore Abott's formula was not applied. The result revealed that Bendiocarb and Alphacympermethrin caused $100 \%$ and $98 \%$ mortalities respectively on the vectors. The carbamate (Propoxur) and organophosphate (Primiphos-Methyl) recorded $65 \%$ and $59 \%$ mortality respectively. None of the other insecticides- Lambdacyhalothrin (48\%), Deltamethrin (40\%), DDT (37\%), and Permethrin (25\%) -recorded $50 \%$ mortality after the $24 \mathrm{hrs}$ post exposure periods.

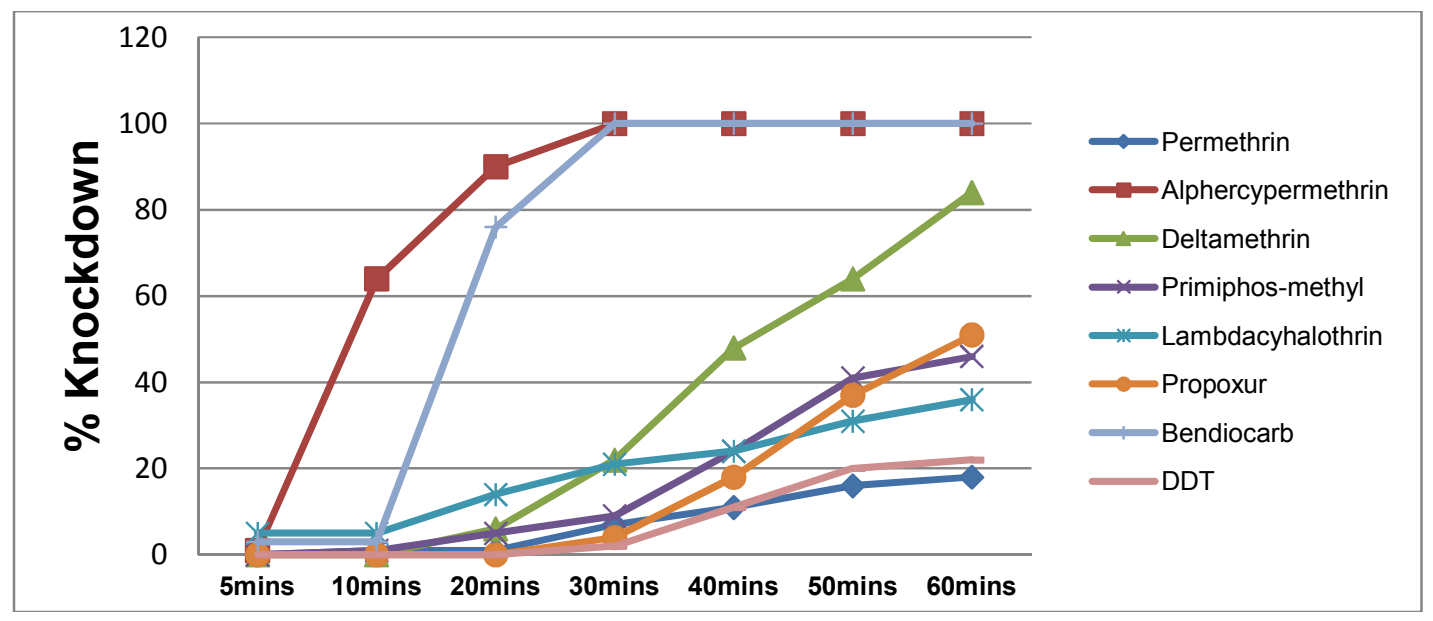

Fig. 2. Percentage (\%) knockdown of Anopheles gambiae s.l exposed to IRS insecticides

Table 1. Toxicity and knock- down time of Anopheles gambiae (s.l) exposed to public health insecticides

\begin{tabular}{|c|c|c|c|c|}
\hline Insecticides & $\% \mathrm{KD}_{1 \mathrm{~h}}$ & $\mathbf{N}$ & $\mathrm{KDT}_{50}(95 \% \mathrm{Cl})$ & $\mathrm{KDT}_{95}(95 \% \mathrm{C} 1)$ \\
\hline DDT & 22 & 100 & $80.9(67.4-100.7)$ & $170.4(131.4-248.9)$ \\
\hline Bendiocarb & 100 & 100 & $15.4(12.8-18.0)$ & $32.4 \quad(27.1-40.9)$ \\
\hline Propoxur & 51 & 100 & $61.7(53.8-72.6)$ & $130.1(104.6-179.7)$ \\
\hline Primiphos-methly & 46 & 100 & $58.8(51.2-68.4)$ & $123.9(101.0-167.2)$ \\
\hline Lambdacyhalothrin & 36 & 100 & $59.7(51.0-69.6)$ & $125.7(103.5-165.5)$ \\
\hline Alphacympermethrin & 100 & 100 & $9.0(7.4-11.3)$ & $19.6(16.1-25.0)$ \\
\hline Deltamethrin & 84 & 100 & $41.9(36.9-47.4)$ & $88.3(74,3-113.6)$ \\
\hline Permethrin & 14 & 100 & $83.8(68.6-105.3)$ & $176.6(135.9-256.3)$ \\
\hline
\end{tabular}


Table 2. Susceptibility status of Anopheles gambiae s.l after $24 \mathrm{hr}$ post exposure period

\begin{tabular}{|c|c|c|c|c|c|c|c|}
\hline Insecticides & $\begin{array}{l}\text { Total no } \\
\text { tested }\end{array}$ & $\begin{array}{l}\text { Total no } \\
\text { dead }\end{array}$ & Percentagemortality & $\begin{array}{l}\text { Total no. Tested } \\
\text { (control) }\end{array}$ & Total No. Dead(control) & $\begin{array}{l}\text { Percentage } \\
\text { Mortality }\end{array}$ & $\begin{array}{l}\text { Susceptibility } \\
\text { status }\end{array}$ \\
\hline Lambdacyhalothrin & 100 & 48 & ${ }^{*} 48$ & 50 & 2 & 4 & Resistant \\
\hline Bendiocarb & 100 & 100 & $* * * 100$ & 50 & 0 & 0 & Susceptible \\
\hline Primiphos-methyl & 100 & 59 & *59 & 50 & 0 & 0 & Resistant \\
\hline DDT & 100 & 37 & *37 & 50 & 1 & 2 & Resistant \\
\hline Permethrin & 100 & 25 & 25 & 50 & 1 & 2 & Resistant \\
\hline Deltamethrin & 100 & 40 & *40 & 50 & 0 & 0 & Resistant \\
\hline Alphacympermethrin & 100 & 98 & $* * * 98$ & 50 & 0 & 0 & Susceptible \\
\hline Propoxur & 100 & 65 & ${ }^{*} 65$ & 50 & 1 & 2 & Resistant \\
\hline
\end{tabular}




\section{DISCUSSION}

The result from the present study demonstrated that the field population of Anopheles gambiae s.I from the Rivers State sentinel site is highly susceptible to the carbamate, Bendiocarb and resistant to the pyrethroids, (Deltamethrin, Lambdacyhaloathrin and Permethrin), organochlorine (DDT), carbamate (Propoxur), and organophosphate (Primiphos-Methyl). The vectors also showed some level of susceptibility to Alphacympermethrin.

Complete susceptibility to Bendiocarb has been recorded in Nigeria [23,24,25] and other African countries [26]. Reports from Equatorial Guinea, Namibia, Mozambique, Mexico, Benin and India have also shown the good performance of Bendiocarb as an indoor residual spraying treatment against mosquito vectors [27].

Resistance of An.gambiae s.I to multiple classes of insecticides has been reported elsewhere in Nigeria [28,29,30].

The level of insecticide resistance reported in the present study portends great danger to the continued use of long-lasting insecticidal nets (LLIN) and indoor residual spraying (IRS) in this area.

High level of resistance found in both DDTand pyrethroids in this study is consistent with earlier findings. Cross-resistance between DDT and the pyrethroids has been reported in An.gambiae $[5,31,32,25]$. [33] also confirmed resistance of Anopheles mosquitoes to DDT and the pyrethroids (Deltamethrin, Permethrin and Lambdacyhalothrin) in SouthWest, Nigeria.

The observed DDT and pyrethroids resistance in this zone is not surprising given the numerous reports of insecticides resistance in other African countries [34,35]. DDT and pyrethroid insecticides are used for IRS, LLINs and for personal protection including controlling crop pests in agriculture. Although no IRS has been carried out at the sentinel site, the mass deployment of LLINs in the area coupled with the applications of local insecticides of unknown chemical composition and normal household insecticides may have contributed to the build-up of insecticide resistance in the local mosquito populations. This continuous exposure of mosquitoes to pyrethroids as well as other commonly used insecticides contributes to mosquitoes becoming strongly resistant to them [3].
The high DDT resistance observed may be that DDT pressure is still available despite the fact that DDT is not used anymore for the control of malaria [36]. This portends danger and calls for more concern and proper monitoring of the chemicals used for pest control.

The relatively higher level of $\mathrm{KD}_{50}$ and $\mathrm{KD}_{95}$ recorded for both DDT and permethrin indicate the existence of KDR mutations in the population of the vectors as suggested by [34]. The comparably low values recorded for other insecticides also suggest the presence of other mechanisms of resistance in the populations [37].

Resistance of mosquitoes to insecticides usually arises through one of two mechanisms, or a combination of the two; metabolic resistance due to increased production of detoxifying enzymes and target site resistance due to mutations in the sodium channels, Acetylcholinestrase or GABA receptor $[38,39]$.

Variation in insecticide resistance mainly depends upon the type of insecticide and frequency of use. Excessive and unwanted usage of insecticides not only increases vector resistance, but also results in cross resistance to other insecticides [40]. Although various mechanisms of insecticide resistance in insects such as metabolic resistance (i.e. esterases, monooxigenase or glutathione-s-transferase), resistance due to reduced penetration or behavioural resistance are reported in several vectors, generally, it is governed by either involvement of metabolic mechanisms or alterations at target sites. Revealing the mechanism of resistance is equally important as that of monitoring resistance in mosquito vectors.

Effective insecticide resistance management is highly essential in preventing resistance, regaining susceptibility or delaying the development of resistance in mosquitoes to support and improve public health [41].

Detection of resistance suggests a change in insecticide class as part of a proactive resistance management programme and in line with the principles of the global plan for insecticide resistance management. In addition, updating the general public on the level of the resistance status of malaria vectors locally and exploiting such information fully is mandatory for improved programmatic decision-making, and to ensure continued impact of implemented vector control interventions on malaria morbidity and mortality. 


\section{CONCLUSIONS}

Our study showed that the populations of Anopheles gambiae s.l around the Rivers State sentinel site have developed resistance to a broad range of insecticides including pyrethroids, Primiphos-Methyl (organophosphate) and DDT (organochlorine). The vectors are susceptible to Bendiocarb (carbamate) and Alphacympermethrin (Pyrethroid). Our finding on the complete susceptibility to carbamate in malaria vectors suggests that bendiocarb insecticides are a potentially effective insecticide for IRS. This finding has critical implications in guiding malaria vector control in Rivers State.

This study provides baseline information for monitoring the status of insecticide resistance in Rivers State.

\section{ACKNOWLEDGEMENT}

We greatly acknowledge the USAID/ PMI-AIRS Project, Nigeria for providing the fund for this project. We would also like to thank Abt associates, the project consultants for their logistics support and providing the necessary materials for the research. Our gratitude also goes to the National Malaria Elimination Project (NMEP) for coordinating the research and to the host community for providing security and an enabling environment for the successful completion of the research work.

\section{COMPETING INTERESTS}

Authors have declared that no competing interests exist.

\section{REFERENCES}

1. Hemingway J, Bates I. Malaria: Past problems and future prospects. After more than a decade of neglect, malaria is finally black on the agenda for both biomedical research and public health politics. EMBO Rep. 2003;4:S29-31.

2. Nigerian Demographic and Health Survey. Federal Ministry of Health, Abuja; 2011.

3. Loroño-Pino MA, García-Rejón JE, Machain-Williams C, Gomez-Carro S, Nuñez-Ayala G, del Rosario NVM. Towards a casa segura: A consumer product study of the effect of insecticidetreated curtains on Aedes aegypti and dengue virus infections in the home. Am J Trop Med Hyg. 2013;89:385-397.
4. Diabate A, Baldet T, Chandre F, Akogbeto M, Guiguemde TR, Darriet F, Brengues C, Guillet $P$, Hemingway J, Small $G H$, Hougard JM. The role of agricultural use of insecticides in resistance to pyrethroids in Anopheles gambiae s.l in Burkina Faso. Am J Trop Med Hyg. 2002;67:617-622.

5. Corbel V, N'Guessan R. Distribution, mechanisms, impact and management of insecticide resistance in malaria vectors: $A$ pragmatic review. In: Manguin $S$, editor. Anopheles mosquitoes - New insights into malaria vectors. Rijeka: InTech; 2013.

6. N'Guessan R, Corbel V, Akogbéto M, Rowland M. Reduced efficacy of insecticide-treated nets and indoor residual spraying for malaria control in pyrethroid resistance area, Benin. Emerg Infect Dis. 2007;13(2):199-206.

7. Asidi A, N'Guessan R, Akogbeto M, Curtis C, Rowland M. Loss of household protection from use of insecticide-treated nets against pyrethroid-resistant mosquitoes, benin. Emerg Infect Dis. 2012;18(7):1101-1106.

8. Trape JF, Tall A, Diagne N, Ndiath O, Ly $A B$, Faye J. Malaria morbidity and pyrethroid resistance after the introduction of insecticide-treated bednets and artemisinin-based combination therapies: A longitudinal study. Lancet Infect Dis. 2011;11(12):925-932.

9. McCann R, Ochomo E, Bayoh MN, Vulule JM, Hamel MJ, Gimnig JE. Reemergence of Anopheles funestus as a vector of Plasmodium falciparum in western Kenya after long-term implementation of insecticide-treated bed nets. Am J Trop Med Hyg. 2015;90(4):597-604.

10. Strode C, Donegan S, Garner P, Enayati AA, Hemingway J. The impact of pyrethroid resistance on the efficacy of insecticide-treated bed nets against African anopheline mosquitoes: Systematic review and meta-analysis. Plos Med. 2014;11(3):e1001619.

11. Churcher TS, Lissenden N, Griffin JT, Worrall $E$, Ranson $H$. The impact of pyrethroid resistance on the efficacy and effectiveness of bednets for malaria control in Africa. Elife. 5; 2016.

DOI: $10.7554 /$ eLife. 16090

12. Ranson $\mathrm{H}$, Lissenden $\mathrm{N}$. Insecticide resistance in African Anopheles mosquitoes: A worsening situation that needs urgent action to maintain malaria 
control. Trends Parasitol. 2016;32(3):187196.

13. WHO. Global plan on insecticide resistance management in malaria vectors (GPIRM). Genera, World Health Organization; 2012.

14. Ranson $\mathrm{H}$, Abdallah $\mathrm{H}$, Badodo $\mathrm{A}$, Guelbeogo WM, Kerah-Hinzoumbé C, Yangalbé-Kalnoné E, Sagnon N, Simard F, Coetzee $M$. Insecticide resistance in Anopheles gambiae: Data from the first year of a multi-country study highlight the extent of the problem. Malaria Journal. 2009;8:299.

15. Liu N. Insecticide resistance in mosquitoes: Impact, mechanisms, and research directions. Annu Rev, Entomol. 2015;60: 537.

16. Hemingway J, Ranson $H$. Insecticide resistance in insect vectors of human disease. Annu Rev Entomol. 2000;45:371391.

17. David JP, Ismail HM, Chandor-Proust A, Paine MJ. Role of cytochrome P450s in insecticide resistance: Impact on the control of mosquito-borne diseases and use of insecticides on Earth. Philos Trans R Soc Lond B Biol Sci. 2013;368(1612): 20120429.

18. Wajala CL, Mgbugi JP, Ototo E, George M, Afrane YA, Atieli HE, Zhou G, Githeko AK, Yan G. Pyrethroids and DDT resistance and organophosphate susceptibility among Anopheles spp. mosquitoes, Western Kenya. Emerg. Infec Dis. 2015;21(12): 2178-2181.

19. Gillies M, DeMeillon B. The Anophelinae of Africa South of the Sahara (Ethiopian zoogeographical region). Johannesburg: South African Medical Research Institute; 1968.

20. Gillies MT, Coetzee M. Supplement to the Anophelinae of Africa South of the Sahara (Afrotropical region). Publ S Afr Inst Med Res. 1987;55:143.

21. World Health Organization. Test procedures for insecticide resistance monitoring in malaria vectors, bio-efficacy and persistence of insecticides on treated surfaces. Geneva, Switzerland, World Health Organization; 1998.

22. WHO. Test procedures for insecticide resistance monitoring in malaria vectors mosquitoes. Geneva, Switzerland: World Health Organization, WHO press; 2013.

23. Okorie PN, Ademowo OG, Irving H, KellyHope LA, Wondji CS. Insecticide susceptibility of Anopheles coluzzii and Anopheles gambiae mosquitoes in Ibadan, Southwest, Nigeria. Medical Veterinary Entomology. 2015;29(1):44-50.

24. Ebere N, Nwakanma OB. Susceptibility of Anopheles gambiae s.l. to carbamate insecticides in Rivers Port Harcourt Metropolis. Journal of Malaria Research and Phytochemicals. 2015; 2(1).

25. Nwankwo EN, Okorie PN, Acha CT, Okonkwo OE, Nwangwu UC, Ezihe Ebuka $\mathrm{K}$. Insecticide resistance in Anopheles gambiae s.I Mosquitoes in Awka, Anambra State, Southeast Nigeria. Journal of Mosquito Research. 2017;7(5):32-38.

26. Aikpon R, Agossa F, Osse R, Oussou O, Aizoun N, Oke-Agbo F, Akogbeto M. Bendiocarb resistance in Anopheles gambiae s.l populations from Atacora department in Benin, West Africa: A threat for malaria vector control. Parasites and Vectors. 2013;6:192.

27. Akogbéto MC, Gil Germain Padonou, Dina G, Seth I, Anges Y. Bendiocarb, a potential alternative against pyrethoid resistant Anopheles gambiae in Benin, West Africa. Malaria Journal. 2010;9:204.

28. Oduola AO, Olojede JB, Ashiegbu CO, Olufemi A, Otubanjo OA, Awolola TS. High level of DDT resistance in the malaria mosquito: Anopheles gambiae s.l. from rural, semi urban and urban communities in Nigeria, Journal of Rural and Tropical Public Health. 2010;9:114-120.

29. Oduola AO, Idowu ET, Oyebola MK, Adeogun AO, Olofede JB, Otubanjo OA, Awolola TS. Mosquitoes resistance to DDT and deltamethrin insecticides in Lagos, Southwest, Nigeria. Parasite Vectors. 2012;5:116.

30. Riveron JM, Chiumia M, Menze BD, Barnes KG, Irving H, Ibrahim SS, Weedall GD, Mzilahowa T, Wondij CS. Rise of multiple insecticide resistance in Anopheles funestus in Malawi: A major concern for malaria vector control. Malaria Journal. 2015;4:344.

31. Protopopoff N, Matowo J, Malima R, Kavishe R, Kaaya R, Wright A, West PA, Kleinschmidt I, Kisinza W, Mosha FW, Rowland M. High level of resistance to pyrethroids and DDT and reduced susceptibility to bendiocarb in malaria vector Anopheles gambiae in North Western Tanzania. Malaria Journal. 2013; 12:149. 
32. Luisa N, Riann NC, Nanette C, Lizette LK. DDT and pyrethroid resistance in Anopheles arabiensis from South Africa. Parasites and Vectors. 2013;6:229.

33. Awolola ST, Adeogun AO, Olojede JB, Oduola AO, Oyewole IO, Amajoh CN. Impact of Perma Net 3.0 on entomological indices in an area of pyrethroid resistant Anopheles gambiae in south-western Nigeria. Parasite Vectors. 2014;7:236.

34. Chandre F, Darrier F, Manger L, Akogbeto M, Faye O, Mouchet J, Gullet P. Status of pyrethroid resistance in Anopheles gambiae sensu lacto. Bull World Organ. 1999;77:220-234.

35. Hargreaves K, Koekemoer LL, Brooke BD, Hunt RH, Mthembu J, Coetzee M. Anopheles funestus resistant to pyrethroid insecticides in South Africa. Med Vet Entomol. 2000;14:181-189.

36. Van Bortel W, Trung Ho D, Thuan LK, Sochantha T, Socheat D, Sumrandee C, Baimai V, Keokenchanh K, Samalane P, Roelants $\mathrm{P}$, Denis L, Verhaeghen $\mathrm{K}$, Obsomer V, Coosemans $H$. The insecticide resistance status of malaria vectors in the Mekong region. Malaria Journal. 2008;7:102.

37. Adeogun AO, Popoola KO, Oduola AO, Olakiigbe OK, Awolola ST. High level of
DDT resistance and reduced susceptibility to deltamethrin in Anopheles gambiae, Anopheles coluzzi, and Anopheles arabiensis from Urban Communities in Oyo State, South-West Nigeria. Journal of Mosquito Research. 2017;7(16):125-133.

38. Hemingway J, Hawkes NJ, McCarroll L, Ranson $H$. The molecular basis of insecticide resistance in mosquitoes. Insect Biochem Mol Biol. 2004;34:653-665.

39. Verhaegen $\mathrm{K}$, Bortel VM, Trung $\mathrm{DH}$, Sochantha $\mathrm{T}$, Keokenchanh $\mathrm{K}$, Coosemans K. Knockdown resistance in Anopheles vagus, An. sinensis, An. paralie and $A n$. peditaeniatus populations of the Mekong region. Parasites and Vectors. 2010;3:9.

40. Tikar SN, Mendki MJ, Sharma AK, Sukumaran D, Veer V, Prakash $\mathrm{S}$, Parashar BD. Resistance status of the malaria vector mosquitoes, Anopheles stephensi and Anopheles subpictus towards Adulticides and Larvicides in arid and semi-arid areas of India. J Insect Sci. 2011;11:85.

41. Baffour-Awuah, Annan AA, MaigaAscofare O, Dieudonné SD, Adjei-Kusi P, Owusu-Dabo E, Obiri-Danso K. Insecticide resistance in malaria vectors in Kumasi, Ghana. Parasites \& Vectors. 2016;9:633.

(c) 2019 Ebere et al.; This is an Open Access article distributed under the terms of the Creative Commons Attribution License (http://creativecommons.org/licenses/by/4.0), which permits unrestricted use, distribution, and reproduction in any medium, provided the original work is properly cited.

Peer-review history:

The peer review history for this paper can be accessed here: http://www.sdiarticle3.com/review-history/46056 